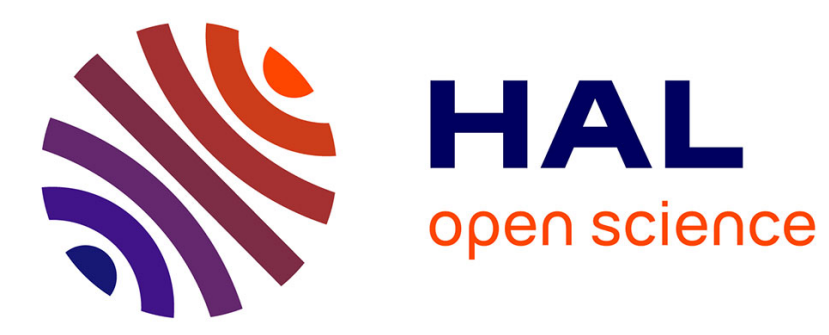

\title{
Origins of the Frog-kick? Alternate-leg Swimming in Primitive Frogs, Families Leiopelmatidae and Ascaphidae
}

\author{
Anick Abourachid, David M. Green
}

\section{- To cite this version:}

Anick Abourachid, David M. Green. Origins of the Frog-kick? Alternate-leg Swimming in Primitive Frogs, Families Leiopelmatidae and Ascaphidae. Journal of herpetology, 1999, 33, pp.657 - 663. hal02017784

\author{
HAL Id: hal-02017784 \\ https://hal.science/hal-02017784
}

Submitted on 13 Feb 2019

HAL is a multi-disciplinary open access archive for the deposit and dissemination of scientific research documents, whether they are published or not. The documents may come from teaching and research institutions in France or abroad, or from public or private research centers.
L'archive ouverte pluridisciplinaire HAL, est destinée au dépôt et à la diffusion de documents scientifiques de niveau recherche, publiés ou non, émanant des établissements d'enseignement et de recherche français ou étrangers, des laboratoires publics ou privés. 


\title{
Origins of the Frog-kick? Alternate-leg Swimming in Primitive Frogs, Families Leiopelmatidae and Ascaphidae
}

\author{
Anick AbOuRachid ${ }^{1}$ AND David M. GReEN ${ }^{2}$
}

\author{
Redpath Museum, McGill University, 859 Sherbrooke St. W., Montreal, Quebec H3A 2K6, Canada
}

\begin{abstract}
When swimming, as when jumping, frogs typically kick synchronously and symmetrically with both hind legs. This is an evolutionarily derived, drag-based mechanism employing the feet as paddles and the hind limbs as thrusters. But morphologically archaic frogs of the genera Leiopelma and Ascaphus, although they jump when on land, obligately swim using alternating leg movements. We video-recorded swimming Leiopelma hochstetteri, L. archeyi, and Ascaphus truei, and other frogs. Leiopelma spp. and Ascaphus always swam with alternating movements of their hind limbs, holding their forelimbs forward and outstretched. One leg always trailed the body acting as a rudder reducing yaw. The frogs swam with near constant velocity and, like swimming tadpoles, the body swung from side to side, pivoting at the level of the otic region. All other species swam with simultaneous and symmetrical movements of the hind limbs, without lateral movement, and with forelimbs pulled back to lie alongside the body; asynchronous leg movements were associated only with mid-water directional changes. The locomotor behavior of Leiopelma and Ascaphus demonstrates that frog jumping and frog swimming are independent locomotor modes with separate evolutionary derivations and neural controls. Therefore, even though the earliest known anurans may have jumped like frogs it does not follow that they swam like frogs.
\end{abstract}

Frogs are notable for their saltatory locomotion: on land they jump and in the water they swim using strong, simultaneous motions of the hind limbs (Kamel et al., 1996; Peters et al., 1996). Anurans evidently became specialized for saltatory locomotion early in their evolution (Shubin and Jenkins, 1995; Jenkins and Shubin, 1998) and the morphological structures associated with jumping readily identify them. Consolidation of the backbone, enhancement of the pelvis and pelvic musculature, loss of the tail, and lengthening of the hind limbs are functionally correlated with this mode of locomotion (Lutz and Rome, 1994). Synchronous leg swimming is also typical and would seem to be facilitated, even demanded, by this morphology. Yet have these jumping and swimming behaviors been necessarily and causatively linked throughout anuran evolutionary history? We examined swimming in the most morphologically archaic living frogs: the genera Leiopelma, endemic to New Zealand, and Ascaphus, from North America (Green and Cannatella, 1994). Although these frogs jump when they are on land, they swim using alternating leg movements.

Swimming in frogs is a drag-based mechanism employing the feet as paddles and the hind limbs as thrusters (Webb, 1988). Specialization to aquatic, arboreal, or terrestrial life

\footnotetext{
${ }^{1}$ Present Address: Laboratoire d'Anatomie Comparée, Muséum Nationale d'Histoire Naturelle, URA 1137 du CNRS, 55 rue Buffon, F-75005 Paris, France.

${ }^{2}$ Corresponding author.
}

among frogs rarely compromise their ability to swim; good jumpers like Rana pipiens swim as ably as specialized aquatic frogs like Hymenochirus boettgeri (Gal and Blake, 1987). Synchronous-leg swimming occurs even in advanced species that primarily walk or crawl, such as many bufonid toads.

Casual observations indicated that frogs of the genera Leiopelma and Ascaphus may not habitually swim with the motion typical of other frogs. Leiopelma hochstetteri is a semi-aquatic, riparian species that is usually found under rocks close to the edge of streams and seepages (Turbot, 1942; Bell, 1982; Green and Tessier, 1990). The feet are fully webbed and the frog will preferentially leap into the stream and dive to the bottom when disturbed. Although $L$. hochstetteri preferentially hops when on land, it has been observed to swim using alternating leg movements rather than the synchronous kick typical of frogs (Turbott, 1942; Whitaker and Hardy, 1985). Ascaphus truei is also a riparian species, endemic to the Pacific Northwest of North America whereas $L$. archeyi is fully terrestrial. There are no previous reports on the manner of swimming of either of these two species.

\section{Methods AND MATERIALS}

We individually video-recorded swimming in five Leiopelma hochstetteri, three L. archeyi, and three Ascaphus truei using a high resolution Panasonic Ws-S050 video camera at 30 frames/ sec. The frogs were made to swim in a $55 \mathrm{~cm}$ long aquarium containing about $12 \mathrm{~cm}$ of water at 17 C. A reference grid on the aquarium bottom was 


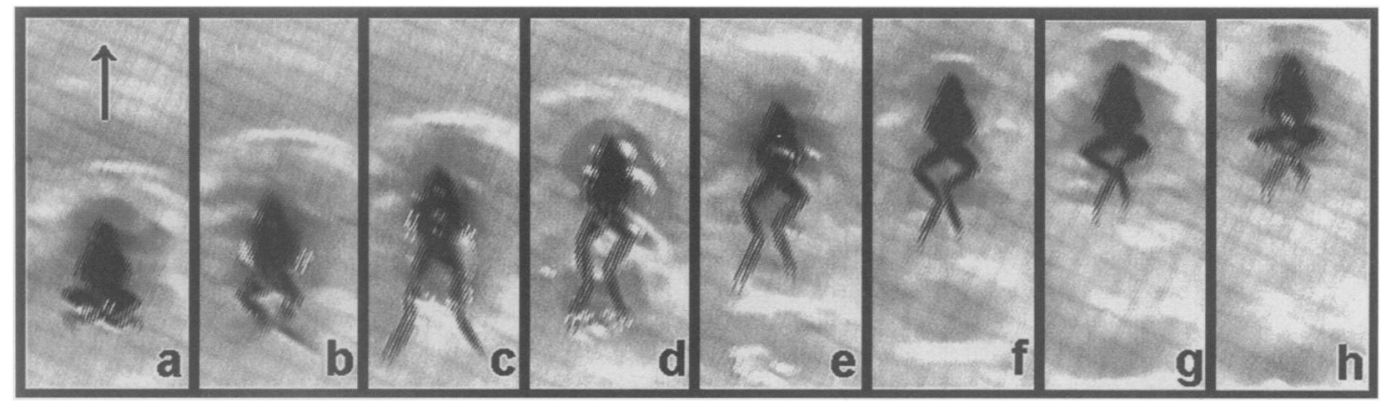

FIG. 1. Complete movement cycle during normal rapid swimming in the derived, neobatrachian frog, Rana sylvatica. As in subsequent figures (Figs. 2-4), these are sequential video images at $30 \mathrm{frames} / \mathrm{sec}$. taken against $1 \mathrm{~cm}^{2}$ background grid. The arrow indicates the direction of locomotion. During the propulsive, extension phase of movement, the flexed hind legs (a) are rapidly extended (b, c), accelerating the frog to a momentary maximum velocity of $50 \mathrm{~cm} / \mathrm{sec}$ between frames $\mathrm{c}$ and d. Velocity decreases to $6 \mathrm{~cm} / \mathrm{sec}$ as the legs are again flexed (e-h) following, in this sequence, a very brief glide phase (d). This frog is swimming at the water's surface and thus waves caused by the bow front as the frog's snout pushes into the water and the wake as the frog's legs push against the water are visible. A jet of turbulence is also visible between the thrusting hind legs (c-e). Leg movements are nearly symmetrical, forelimbs are adpressed, and there is no deflection from the direction of locomotion.

composed of $1 \mathrm{~cm}$ squares and a $45^{\circ}$ inclined mirror placed in the aquarium reflected the lateral view to the overhead camera. For comparison, we also examined swimming in two Bombina variegata (Bombinatoridae), two Bufo viridis (Bufonidae), four Rana sylvatica (Ranidae), and two Hyla crepitans (Hylidae). Bombinatoridae is the next most primitive clade to Leiopelmatidae and Ascaphidae among frogs (Ford and Cannatella, 1993), whereas the other species represented the more phylogenetically derived neobatrachian frogs.

From the videos, swimming sequences long enough to show at least one complete cycle of movements for a frog (unimpeded by the sides of the aquarium) were analyzed frame by frame. On each frame, 15 points were digitized directly from a TV screen using JAVA software to yield Cartesian coordinates for each point. The points were: the end of the toes, the phalangeal articulation, the ankle, the knee, the hand, and the shoulder of each side, the vent, the snout, and an invariant point on the background field. The articular angles of the limbs were calculated from the Cartesian coordinates and results were plotted against time. Maximum flexion of the leg was used as the standard to indicate the beginning of one movement cycle, thus the first phase of the cycle is extension of the leg, followed by the glide, if present, then flexion. During the glide phase in typical frog swimming, the leg remains extended while the frog relies upon its momentum to carry it forward (Peters et al., 1996) The maximum amplitude of movements of each articulation was calculated for all cycles.

\section{RESULTS}

All derived species, exemplified by Rana sylvatica (Fig. 1) and Bombina variegata, swam with simultaneous and symmetrical movements of the hind limbs, without lateral movement, and with forelimbs pulled back to lie alongside the body. Swimming velocity rose with each thrust and fell upon each recovery stroke (Fig. 1). Asynchronous movements of the legs were associated only with mid-water directional changes. The extension and flexion phases of the leg movements in synchronous kicking species such as Bombina variegata were identical in form to those of Leiopelma hochstetteri (Table 1) but in rapid swimming flexion began immediately af-

TABLE 1. Angular extension and amplitude (in degrees) while swimming for joints in the legs of an alternate-leg swimming frog (Leiopelma) and a synchronous-leg swimming frog (Bombina).

\begin{tabular}{lccccccc}
\hline \hline & \multicolumn{3}{c}{ Leiopelma hochstetteri } & & \multicolumn{2}{c}{ Bombina variegata } \\
\cline { 2 - 4 } \cline { 6 - 8 } & Maximum & Minimum & Amplitude & & Maximum & Minimum & Amplitude \\
\hline Hip & $173 \pm 4$ & $105 \pm 20$ & $66 \pm 19$ & & $174 \pm 3$ & $107 \pm 15$ & $69 \pm 15$ \\
Knee & $173 \pm 7$ & $46 \pm 10$ & $126 \pm 10$ & & $145 \pm 18$ & $43 \pm 4$ & $103 \pm 16$ \\
Ankle & $146 \pm 9$ & $14 \pm 8$ & $132 \pm 11$ & & $121 \pm 15$ & $34 \pm 5$ & $87 \pm 13$ \\
Tarso-metatarsus & $152 \pm 11$ & $87 \pm 11$ & $65 \pm 10$ & & $129 \pm 13$ & $93 \pm 10$ & $35 \pm 10$ \\
\hline
\end{tabular}




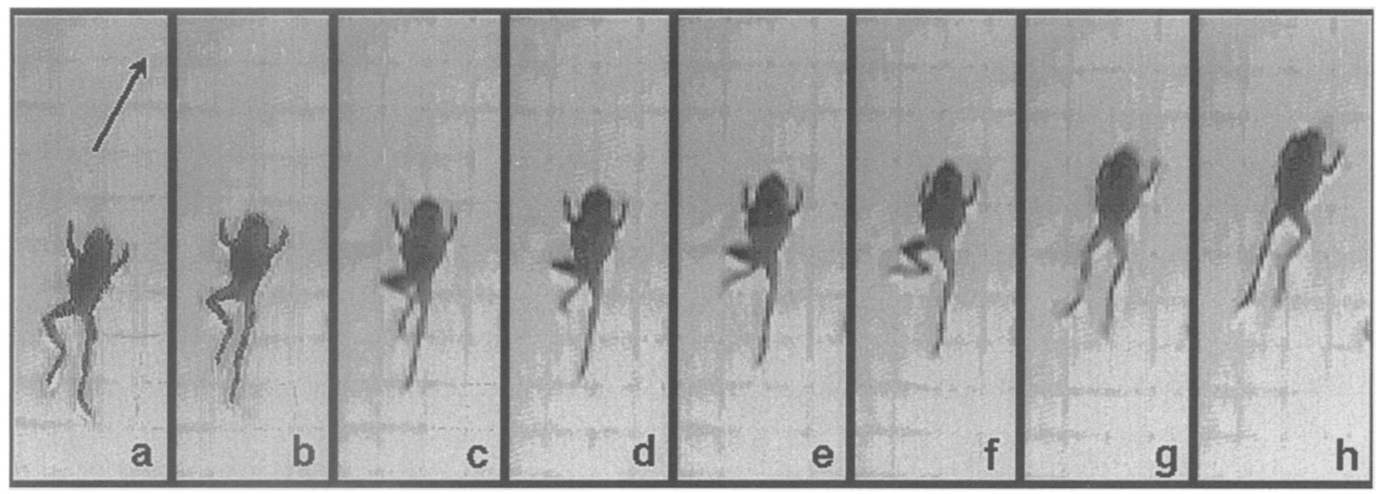

FIG. 2. The primitive frog, Leiopelma hochstetteri, swimming normally underwater. In this sequence, encompassing half of the cycle of movements for each leg, the left leg flexes close to the body (a-d) then extends with a rapid kick $(\mathrm{e}-\mathrm{h})$ beginning with the knee, hip, and phalangeal joints, followed by the ankle. Thereafter, as seen in the right leg (a), the extended limb trails the body with its phalangeal and ankle joints maximally extended $(b-f)$, before once again flexing $(g, h)$. Unlike Rana sylvatica, velocity is near constant, at about $18 \mathrm{~cm} /$ sec. Maximum lateral deflection of the body from the general direction of locomotion, about $30^{\circ}$, occurs when a leg is most flexed (e). Forelimbs are held away from the body, extending forward.

ter maximum extension, omitting the glide phase. The extension phase averaged $35 \%, 32 \%$, $34 \%$ and $35 \%$ of cycle duration in B. variegata, Bufo viridis, Hyla crepitans, and Rana sylvatica, respectively, when the glide was omitted.

Leiopelma hochstetteri, L. archeyi, and Ascaphus truei swam with near identical motions (Figs. 24). These frogs always alternated movements of their hind limbs when swimming, with their forelimbs held forward and outstretched. After an initial two-legged launch upon entering the water or as an escape behavior, which employed both hind legs simultaneously, they would immediately change to alternate-leg swimming by flexing one leg (Fig. 4). At all times, one leg or the other trailed the body in the glide phase, evidently employed as a rudder to prevent excessive yaw. The frogs swam with near constant velocity and, like swimming tadpoles (Wassersug, 1989), the body swung from side to side, pivoting at the level of the otic region.

Movements of the hind limbs in swimming Leiopelma spp. and Ascaphus, though not simultaneous, were symmetrical and consisted of distinct extension, glide, and flexion phases (Figs. 5,6 ). Extension, a rapid kick taking up $34 \%$ of the cycle, began at the knee, hip, and phalangeal joints, followed by the ankle joint. In the ensuing glide phase, occupying $26 \%$ of cycle duration, the extended leg trailed behind the body, hip and phalangeal joints extended slightly, and the hip joint began to flex. Phalangeal and ankle

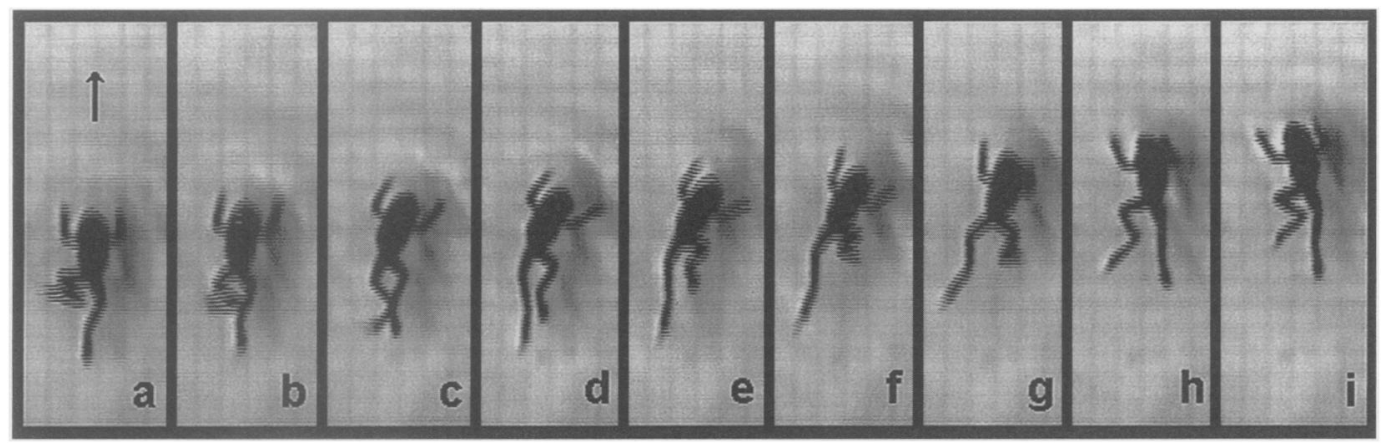

FIG. 3. Leiopelma archeyi, swimming at the water's surface. This sequence encompasses a full cycle of movements for each leg, beginning with extension of the flexed left leg $(a-d)$ as the right leg is held behind in its glide phase. The right leg flexes and extends $(\mathrm{d}-\mathrm{g})$ while the left leg remains extended. Only once it is fully extended, does the left leg flex again ( $h, i)$. Maximum lateral deflection of the body (e) from the general direction of locomotion is about $30^{\circ}$. As in L. hochstetteri, the forelimbs are held away from the body, extending forward. Although a bow wave is visible, surface waves resulting from the thrusting movements of the hind limbs are not. 


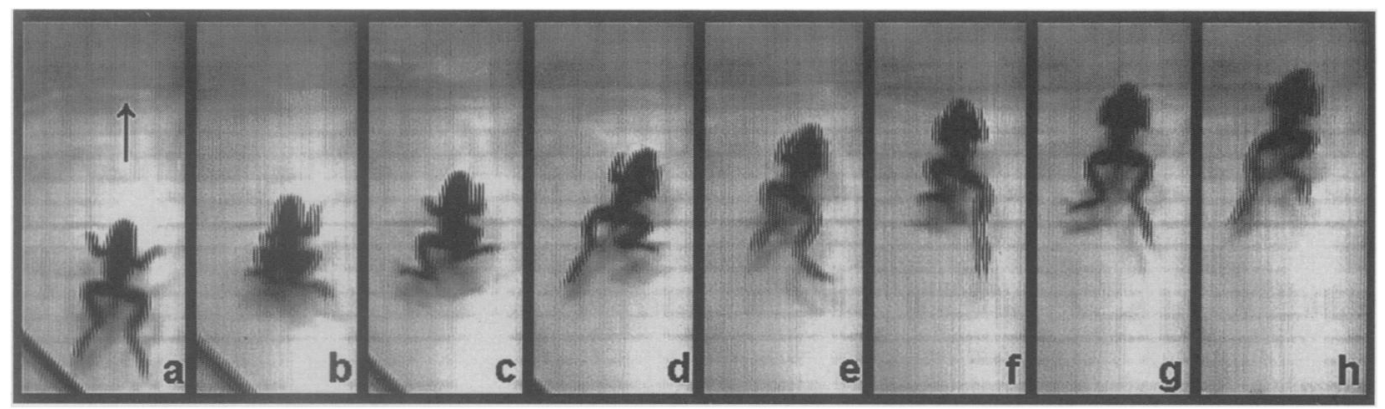

FIG. 4. Transition from escape behaviour to underwater swimming in Ascaphus truei. After being tapped with a stick, the frog made one symmetrical kick and flexed both legs $(a, b)$. Swimming commences with the asymmetrical of the left leg (c) and continues with alternating leg movements without a glide phase between extension and flexion $(\mathrm{d}-\mathrm{h})$.

joints were maximally stretched during this phase, describing an angle of up to $173^{\circ}$, whereas knee and hip were slightly flexed, averaging $126^{\circ}$ and $132^{\circ}$ respectively (Table 1 ). The final, flexion phase, took up $40 \%$ of cycle duration. All articulations contracted as the leg was drawn close to the body until the joints circumscribed angles of only $46^{\circ}$ at the ankle and $14^{\circ}$ at the knee. The hind limbs never flexed completely, as they would whenever the frog was resting on land.

\section{DISCUSSION}

Typically, frogs swim with highly stereotyped, synchronous movements of the hind limbs (Calow and McNeil Alexander, 1973; Gal and Blake, 1988) which are superficially similar to the actions of jumping but in the horizontal plane (Peters et al., 1996). Rapid extension of the leg occurs during the propulsive stroke, followed by leg flexure during a slower recovery stroke. Individual leg movements in all frogs ex- amined were the same; the fundamental difference in swimming between the primitive frogs, Leiopelma spp. and Ascaphus, and other species lay in the timing of the movements of the two hind legs (Fig. 6). Thus swimming as practiced by Leiopelma spp. and Ascaphus is a mode of locomotion seemingly at odds with their specializations for saltatory terrestrial locomotion. Although they are adequate jumpers, Leiopelma spp. and Ascaphus neither employ nor maintain a pattern of synchronous leg movements during normal aquatic locomotion. Amongst other frogs, aquatic, arboreal, or terrestrial specializations rarely compromise swimming ability. Good jumpers like Rana pipiens swim as ably as specialized aquatic frogs like Hymenochirus boettgeri (Gal and Blake, 1987) and synchronousleg swimming occurs even in advanced species that primarily walk or crawl, such as Bufo calamita, which virtually never hops. Many other stream-dwelling frogs, such as $R$. boylii, are strong, synchronous-leg swimmers. Only some

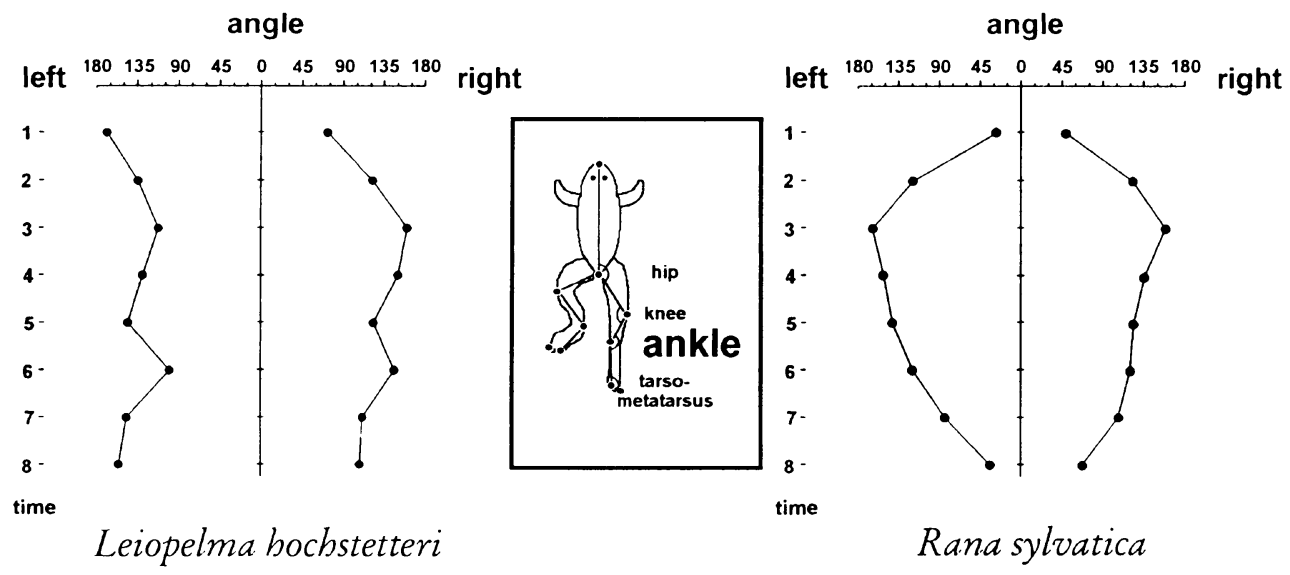

FIG. 5. Comparison of ankle movements (angle of flexion) during a complete locomotor cycle in swimming Leiopelma hochstetteri and Rana sylvatica. 

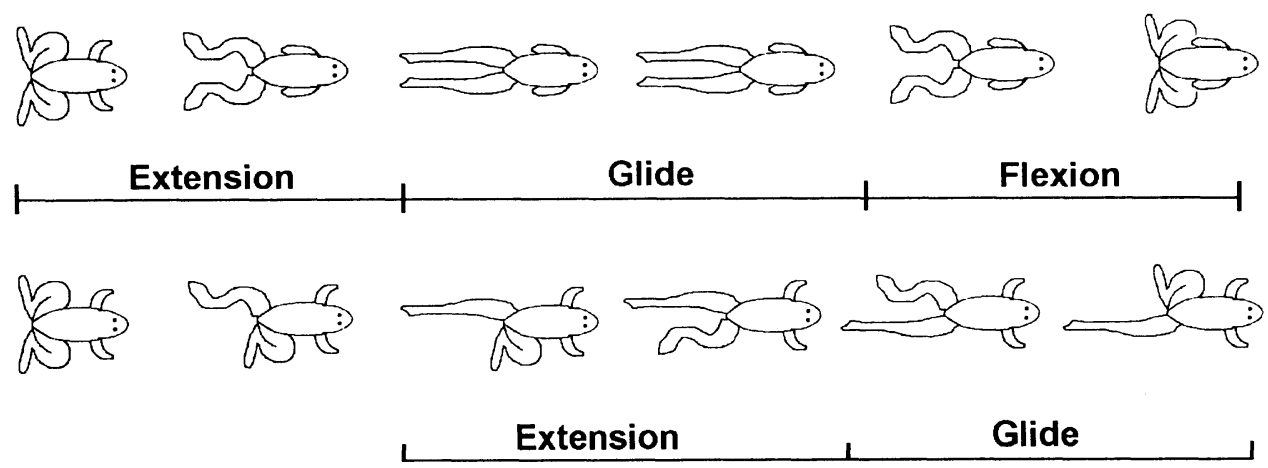

FIG. 6. Diagrammatic comparison of hind limb movements during symmetrical (top) and asymmetrical (bottom) swimming in derived and primitive frogs, respectively. Each movement cycle consists of extension, glide, and flexion phases for each leg. In primitive frog swimming (bottom), the legs are out of phase.

specialized sedentary or fossorial frogs, such as Ceratophrys spp., may prove to be incompetent swimmers (D.M. Green, pers. obs.).

Swimming as practiced by Leiopelma spp. and Ascaphus appears energetically inefficient (Calow and McNeil Alexander, 1973) compared to that of more advanced frogs. It lacks the hydrodynamic, jet-stream thrust provided by coordinated, synchronous motion of the hind legs and feet, as seen in a swimming Rana sylvatica (Fig. 1), for example. Gal and Blake (1988) found that rapid acceleration in the aquatic frog, Hymenochirus boettgeri, at the end of the extension phase is due to such a hydrodynamic interaction of the hind legs providing propulsive thrust. This level of thrust is possible only if the kicks of the hind limbs are synchronous. Typically, in H. boettgeri, asynchronous movements of the legs are associated only with directional changes. Swimming Leiopelma spp. and Ascaphus, though, obviously lack this hydrodynamically coordinated thrust from the legs. The obligate glide phase between extension and flexion, whereby each extended leg trails the body while flexion of the other leg is completed, appears to both compensate for the slower speed of the recovery stroke and be required to provide a rudder. This results in time wasted while swimming, reducing the maximum possible stroke rate for a given energy expenditure. This is not an optimal manner of swimming (Calow and McNeil Alexander, 1973). Furthermore, the simultaneous kick of typical frog swimming allows for rapid changes of direction, especially in contact with the substrate, an escape tactic which Leiopelma spp. and Ascaphus may not have at their disposal. On the other hand, Leiopelma and Ascaphus are able to swim with constant velocity. Like swimming tadpoles (Wassersug, 1989), their heads waggle back and forth, the point of least lateral deflection being at the level of the otic region. The effect of this upon swimming efficiency may be hydrodynamically neutral. Although the wavering snout may be a source of additional drag, the flexion of the body may be a source of additional thrust (Liu et al., 1996). Tadpoles, however, are shaped the way they are because they are constrained to turn into frogs (Wassersug, 1989; Liu et al., 1996).

Because Leiopelma hochstetteri and Ascaphus truei are both stream-dwelling frogs, it may be logical to suppose that their mode of swimming could be related to riparian habitats. Leiopelma hochstetteri, for all its apparent inefficiency as a swimmer, flailing furiously with its legs, nevertheless can move quickly and powerfully under water. But the frogs rarely sustain their swimming movements for long and tend to swim only enough to dive to the bottom of a stream and hide (D.M. Green, pers. obs.). Leiopelma archeyi is strictly terrestrial.

The swimming behavior of Ascaphus and Leiopelma spp. shows that frog-hopping and frogkick swimming are independent locomotor traits, evidently with separate derivations (Fig. 7). Jenkins and Shubin (1998) showed from fossil evidence that the peculiar anatomy associated with jumping in frogs is ancient and that terrestrial saltation is likely the primitive mode of locomotion among anurans. Gans and Parsons (1996) proposed that jumping in frogs evolved initially as an antipredator escape mechanism, enabling a fleeing animal to enter the water as rapidly as possible. Both burst swimming and escape behavior in Leiopelma and Ascaphus use a jump. The derived nature of saltatory locomotion in jumping vertebrates is also mirrored in their ontogeny (Eilam, 1995). For example, gerbils (Gerbillus dasyurus) employ alternating movements in each limb girdle as pups before changing to synchronous-leg jumping in the adult (Blumberg-Feldman and Eilam, 1995). Thus synchronous-leg swimming, like jumping, is also derived. In anurans, the transition from 


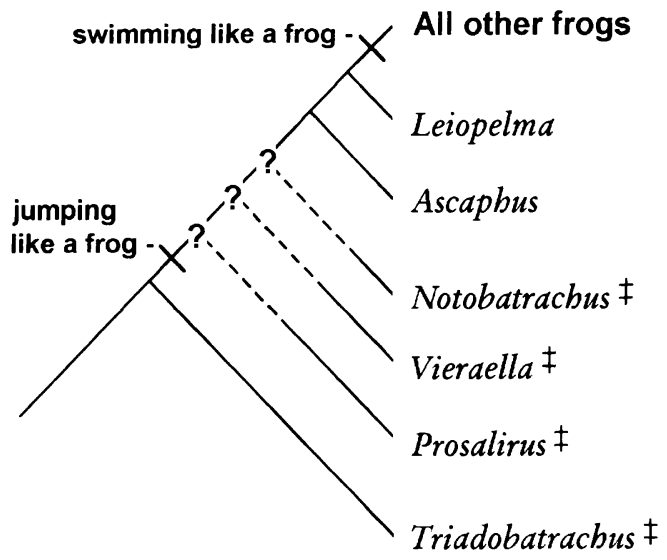

FIG. 7. Phylogenetic hypothesis of living and extinct $(\ddagger)$ primitive anurans, based on Ford and Cannatella (1993) and Shubin and Jenkins (1995), showing early origin of terrestrial jumping (Jenkins and Shubin, 1998) and probable later advent of synchronouslegged swimming among more derived frogs.

tadpole-like behavior to frog-like behavior involves central nervous system maturation, morphological change, and, often, change in habitat preference (Stehouwer, 1992; Stehouwer and Farrel, 1984). Prior to metamorphosis in Xenopus laevis, tadpoles use alternating motions of the hind limbs before they switch to the coordinated kicks of post-metamorphic, adult swimming (Hughes and Prestige, 1967).

Leiopelma and Ascaphus exhibit many primitive anuran features (Green and Cannatella, 1994), including the myology of the pelvic region (Noble, 1922; Dunlap, 1960). Uniquely among living anurans, both Ascaphus and Leiopelma lack condylar or zygapophysial articulations and possess only fibrocartilaginous connections between amphicoelous vertebrae, just as occur in the oldest known fossil anuran, Prosalirus bitis (Jenkins and Shubin, 1998). The mode of aquatic locomotion in Ascaphus and Leiopelma may be yet one more symplesiomorphy. It follows, then, that even though the earliest known anurans, Prosalirus, Vieraella, and Notobatrachus, could have jumped like advanced frogs, it does not mean that they must have swam like advanced frogs.

Acknowledgments.-We thank Renée Fagnou for her fine help on this project, Henry Reiswig for use of his digitizing and image analysis equipment, Robert Lamarche for help with video recording, and David Cundall for discussions on vertebrate locomotion. Kelly McAllister and Bill Leonard assisted in collecting Ascaphus truei. Bruce Waldman and Catherine Tessier, at different times, participated in collecting Leiopelma in New Zealand; we thank the New Zea- land Department of Conservation for permits. This research financed by a grant from NSERC Canada to DMG.

\section{Literature CiTED}

BelL, B. D. 1982. New Zealand frogs. Herpetofauna 14:1-12.

Blumberg-Feldman, H., and D. Eilam. 1995. Postnatal development of synchronous stepping in the gerbil (Gerbillus dasyurus). J. Exp. Biol. 198:363-372.

Calow, L., and R. MCNeil AleXander. 1973. A mechanical analysis of the hindlimb of a frog (Rana temporaria). J. Zool. (London) 171:293-321.

DunlaP, D. G. 1960. The comparative myology of the pelvic appendage in Salientia. J. Morphol. 106:176.

EILAM, D. 1995. Comparative morphology of locomotion in vertebrates. J. Motor Behav. 27:100-111.

FORD, L. S., AND D. C. CANNATELla. 1993. The major clades of frogs. Herpetol. Monogr. 7:94-117.

GAL, J. M., AND R. W. BLAKE. 1987. Hydrodynamic drag of two frog species: Hymenochirus boettgeri and Rana pipiens. Can. J. Zool. 65:1085-1090.

- 1988. Biomechanics of frog swimming. II: Mechanics of the limb-beat cycle in Hymenochirus boettgeri. J. Exp. Biol. 138:413-429.

GANS, C., AND T. S. PARSONS. 1966. On the origin of the jumping mechanism in frogs. Evolution 20:9299.

GREEN, D. M., AND C. TESSIER. 1990. Distribution and abundance of Hochstetter's Frog, Leiopelma hochstetteri. J. Roy. Soc. New Zealand 20:261-268.

- - and D. C. Cannatella. 1994. Phylogenetic significance of the amphicoelous frogs, Ascaphidae and Leiopelmatidae. Ethol. Ecol. Evol. 5:233-245.

Hughes, A., AND M. C. PRestige. 1967. Development of behavior in the hindlimb of Xenopus laevis. J. Zool. (London) 152:347-359.

Jenkins, F. A. AND N. H. SHubin. 1998. Prosalirus bitis and the anuran caudopelvic mechanism. J. Vert. Paleontol. 18:495-510.

Kamel, L. T., S. E. Peters, and D. P. Bashor. 1996. Hopping and swimming in the leopard frog, Rana pipiens: II. Comparison of muscle activities. J. Morphol. 230:17-31.

LiU, H., R. J. Wassersug, AND K. KaWAChI. 1996. A computational fluid dynamics study of tadpole swimming. J. Exp. Biol. 199:1245-1260.

Lutz, G. J., AND L. C. ROME. 1994. Built for jumping: the design of the frog muscular system. Science 263:370-372.

NobLE, G. K. 1922. The phylogeny of the Salientia. I. The osteology and thigh musculature; their bearing on classification and phylogeny? Bull. Amer. Mus. Nat. Hist. 46:1-87.

Peters, S. E., L. T. Kamel, and D. P. Bashor. 1996. Hopping and swimming in the leopard frog, Rana pipiens: I. step cycles and kinematics. J. Morphol. 230:1-16

SHuBIN, N. H., AND F. A. JENKINS. 1995. An early Jurassic jumping frog. Nature 377:49-52.

STEHOUWER, D. J. 1992. Development of anuran locomotion: ethological and neurophysiological considerations. J. Neurobiol. 23:1467-1485.

— AND P. B. FARREL. 1984. Development of hind- 
limb locomotor behavior in the frog. Dev. Psychobiol. 17:217-232.

TurbotT, E. G. 1942. The distribution of the genus Leiopelma in New Zealand with description of a new species. Trans. Roy. Soc. New Zealand 71:247253.

WASSERSUG, R. J. 1989. Locomotion in amphibian larvae (or "Why aren't tadpoles built like fishes?). Amer. Zool. 29:65-84.
WEBB, P. W. 1988. Simple physical principles and vertebrate aquatic locomotion. Amer. Zool. 28:709725 .

WHITAKER, A. H., AND G. S. HARDY. 1985. An unusual frog observation. J. Roy. Soc. New Zealand 15:289290.

Accepted: 21 July 1999.

\title{
Evolution of Herbivory in Lacertid Lizards: Effects of Insularity and Body Size
}

\author{
RAOUL VAN DAMME
}

\author{
Department of Biology, University of Antwerp, Universiteitsplein 1, B-2610 Wilrijk, Belgium
}

\begin{abstract}
I tested the putative correlation between insularity and herbivory in lacertid lizards. Analysis of literature data on 97 populations of 52 species shows that lizard populations on islands more often include plant material in their diet than do mainland populations. To investigate whether this finding reflects adaptation due to recent selection or is merely a product of the phylogenetic history of the populations, I reconstructed the ancestral states for diets and insularity and incorporated them in the analysis. Changes in habitat (island-mainland or mainland-island) often went with changes in diet (herbivore-insectivore or insectivore-omnivore). Insectivorous lizards that find themselves on islands more often turn towards herbivory than do lizards living in mainland situations. Lizards that already have plants in their diet when living on the mainland seem more successful in colonizing islands. Herbivorous populations of lacertids tend to be larger than insectivorous populations, but there is considerable overlap. No difference in mean snout-vent length was found between island and mainland populations.
\end{abstract}

As expected from their great taxonomic diversity, lizards have evolved a great range of diets; insects and other arthropods, mammals and birds, vertebrate eggs, snails, fish, nectar, and various mixtures of leaves, flowers, and fruits. Although the dietary range of lizards is great, the distribution of foods eaten reveals that complete herbivory is rare compared to a diet of arthropods. Only about 3\% of all extant lizard species are known to eat significant quantities of plant food (King, 1996). On the other hand, many species occasionally shift away from a diet only of arthropods, toward an omnivorous or herbivorous diet (e.g., Pough, 1973; Schluter, 1984; Pérez-Mellado and Corti, 1993; King, 1996). Several authors have speculated on the ecological circumstances that could induce insectivorous lizards to expand their diet to include plant material (Pough, 1973; Schluter, 1984; Pérez-Mellado and Corti, 1993; King, 1996). Because plant material is less digestible and may produce substantially slower growth (Pough, 1973; Schluter, 1984), herbivory is often considered a 'forced move', that lizards will not make unless arthropods are insufficient to meet their energy requirements (but see Johnson and Lillywhite, 1979; Sadek, 1981; Troyer, 1984). Lizards living in habitats where insect abundance is (periodically) low may benefit from (partial) herbivory. Large body size is also considered an incentive for herbivory, because larger lizards putatively have greater energetic needs and are less adept at catching small prey because they must move a greater mass in pursuit (Sokol, 1967; Pough, 1973; Sadek, 1981; but see Greene, 1982). The bulk of exclusively herbivorous lizard species is indeed larger than $300 \mathrm{~g}$ (Sokol, 1967; Pough, 1973; but see Greene, 1982).

If the above presumptions are true, insular lizard populations can be expected to feed more often on plant material than mainland populations. Indeed, islands (especially small ones) often have poor arthropod faunas (Janzen, 1973a, b), and at least for some families and genera of lizards, there is a tendency for larger body size in island races (Case, 1978). Although many au- 